\title{
Primary Actinomycosis of the Leg: A Case Report and Literature Review
}

\author{
Dr. Norah Ibrahim Alabdalaaly ", Dr. Mashael Suliman Albahli, Dr. Ayed Ibrahim Almutairi
}

General Surgery, Prince Sultan Military Medical City, 12211, Saudi Arabia

*Corresponding author: Dr. Norah Ibrahim Alabdalaaly; Nora_e_a@hotmail.com

Received 11 December 2021;

Accepted 31 December 2021;

Published 05 January 2022

\begin{abstract}
Actinomycosis is an indolent, slowly progressive, suppurative infection caused by gram-positive branching bacteria of the genus Actinomyces. The disease actinomycosis most commonly occurs in 3 body regions: cervicofacial (55\% of patients), abdominopelvic (20\%), and pulmonothoracic (15\%). Primary infection of an extremity is an uncommon feature of actinomycosis. We present a case of rare primary Actinomycosis of the lower extremity.
\end{abstract}

Keywords: Primary Actinomycosis of the leg, A Case Report, Literature Review

\section{Introduction}

Actinomycosis is an indolent, slowly progressive, suppurative infection caused by gram-positive branching bacteria of the genus Actinomyces ${ }^{[1]}$. The organism is a member of the oral and gastrointestinal microflora of humans ${ }^{[1]}$. The disease actinomycosis most commonly occurs in 3 body regions: cervicofacial (55\% of patients), abdominopelvic (20\%), and pulmonothoracic $(15 \%)^{[1]}$.

Involvement of other parts of the body is uncommon and usually secondary to a lesion in one or the other of the above sites ${ }^{[2]}$. Extremity disease can occur by secondary involvement through direct extension or hematogenous spread. However, primary actinomycosis of an extremity is very rare ${ }^{[2]}$. A case report of Primary actinomycosis of the leg in adult male is presented in this article.

\section{Case report}

A 39-year-old soldier from Saudi Arabia was first seen in the primary health care with a chief complaint of a Right leg swelling progressing over the years. He complains of multiple small wounds with purulent drainage on the Antero-medial aspect of the right leg. The patient was in his usual state of health until approximately 6 years ago, when he noted progressive swelling with purulent discharge from multiple small opening. Patient denied history of trauma. In last year patient were following with dermatology clinic and Infectious diseases in which he was diagnosed as case of Actinomycosis based on histopathology result and started on amoxicillin for one year without improvement.

After that patient referred to general surgery clinic for definitive surgical management.

WWW.ijirms.in
On examination, the patient was afebrile, hemodynamically stable. The systemic examination was negative. Local examination showed a mass in the mid anterior aspect of right leg, measuring $12 \times 12 \mathrm{~cm}$ sparing the proximal and distal joints, with irregular edges, firm, non-mobile, fixed to the underlying tissue. The overlying skin was thick, hyperpigmented, and with multiple dry fistulous tracts, and no subcutaneous crepitus (Figure 1). There were no palpable lymph nodes. Neuro-vascular examination were intact.

Laboratory findings included a white blood cell count of 9,200 , a platelet count of 259,000 , erythrocyte sedimentation rate of 11 , and C-reactive protein of $<1 \mathrm{mg} / \mathrm{L}$. Blood cultures were negative.

Magnetic resonance imaging showing focal prominent hypertrophic subcu-taneous fat of the anterio-medial aspect of the med right leg with mild un-derlying tibial bone cortical chronic erosion. Normal knee joint no signs of osteomyelitis.

A biopsy of the left foot was obtained and show grains surrounded by acute and chronic inflammation with granulation tissue. Grocott methenamine silver (GMS) is negative while gram and periodic acid-schiff (PAS) show filamentous bacterial. The findings are consistent with actinomycetoma. A culture of the biopsy with antibiotic sensitivity was found to be sensitive to penicillin.

The management plan was discussed with the patient, in which he under-went wide local excision with vacuum assisted closure (VAC) (Figure 2,3).

The operative findings were large mass fixed to the bone and fascia with thick exposed tibial bone and multiple sinuses, which was completely ex-cised and shaved from the muscles and bone (Figure 4). 
Five days later; the patient underwent perforator flap coverage.

After 22 days patient was taken for debridement and skin graft coverage of remaining defect on right leg.
Post operatively patient was stable and discharged on good condition after 10 days with Amoxicillin for 6 months as per the infectious disease recom-mendation and regular follow up (Figure 5).

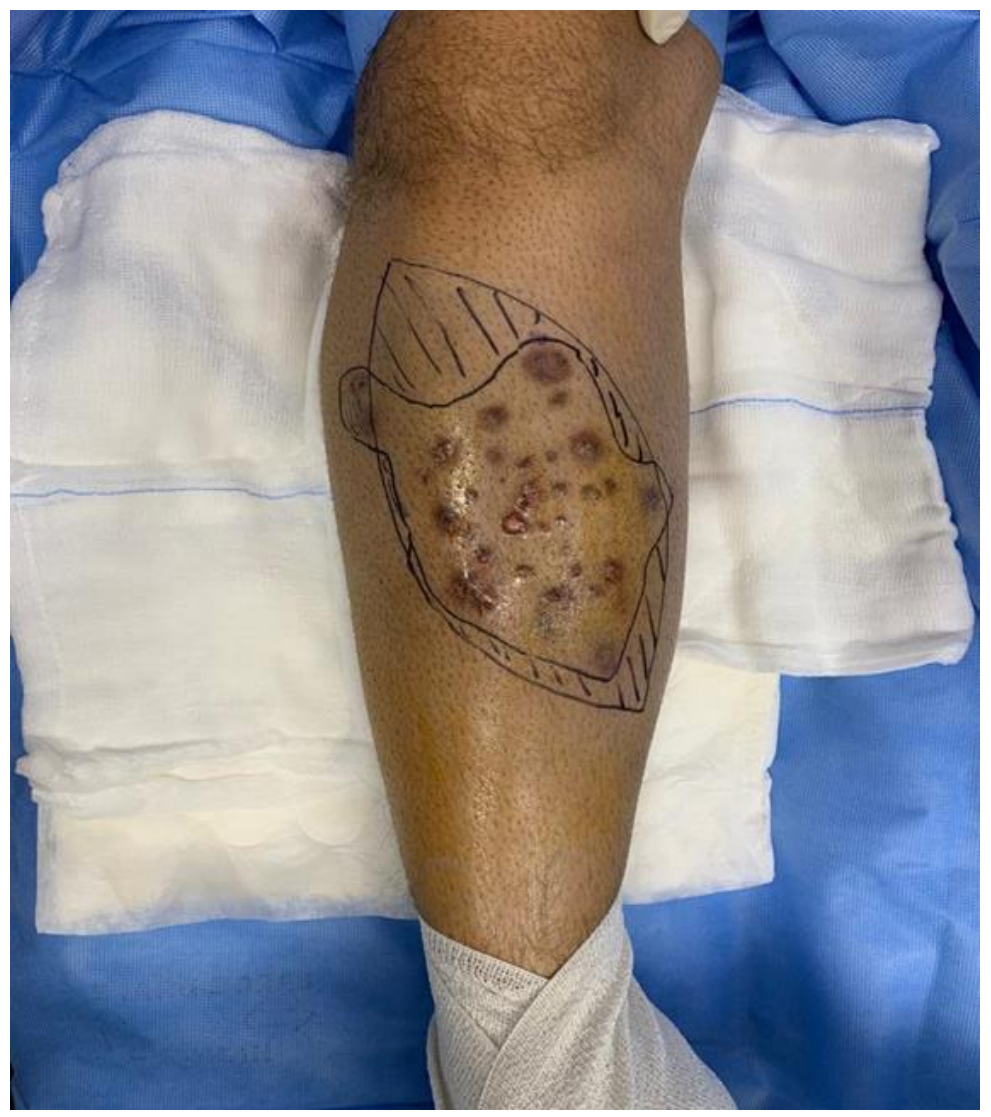

Figure 1: Patient With Actinomycosis leg Infection with Multiple Sinuses.

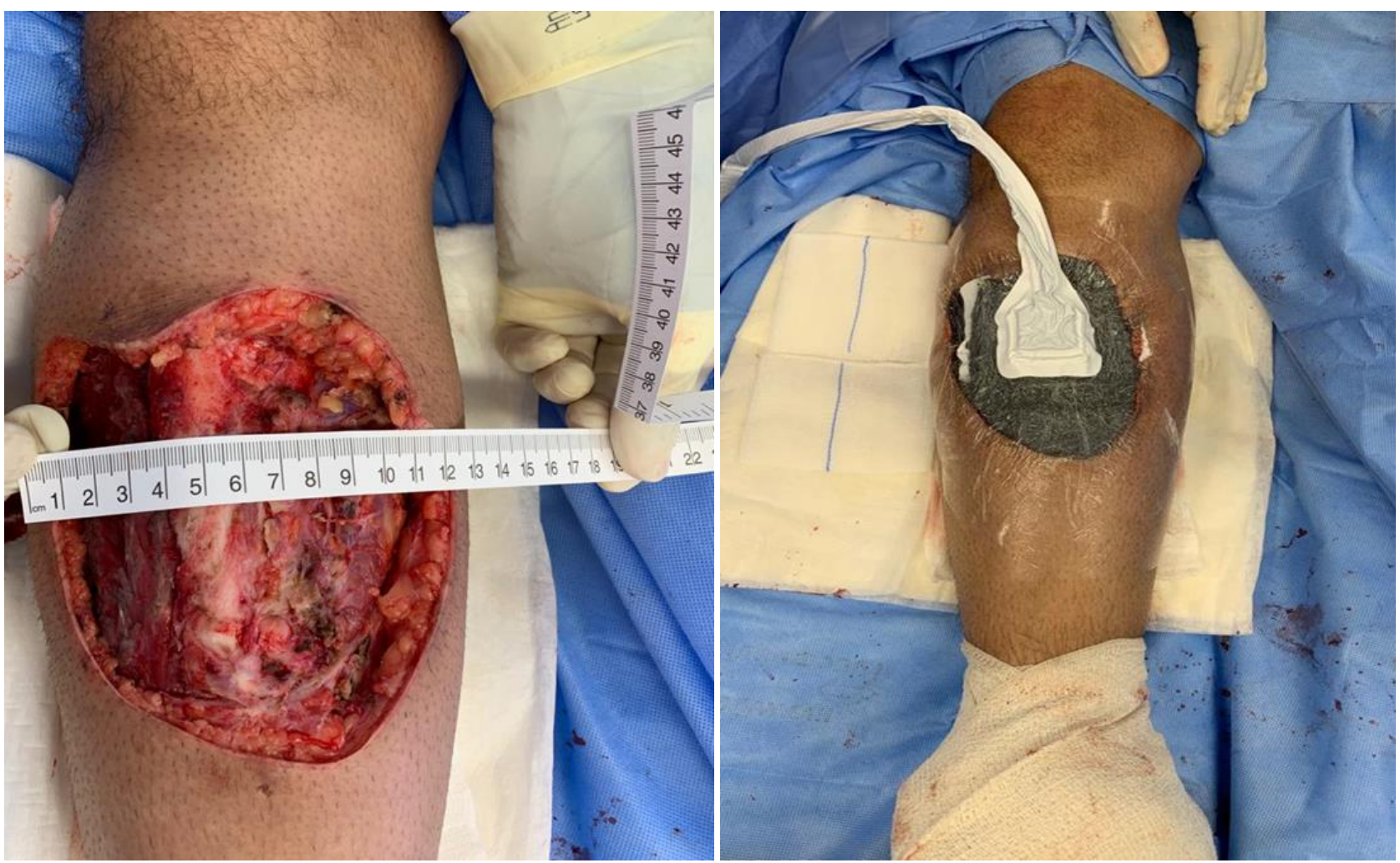

Figure $2 \&$ 3: Wide local excision of right leg mass with vacuum assisted closure (VAC) 


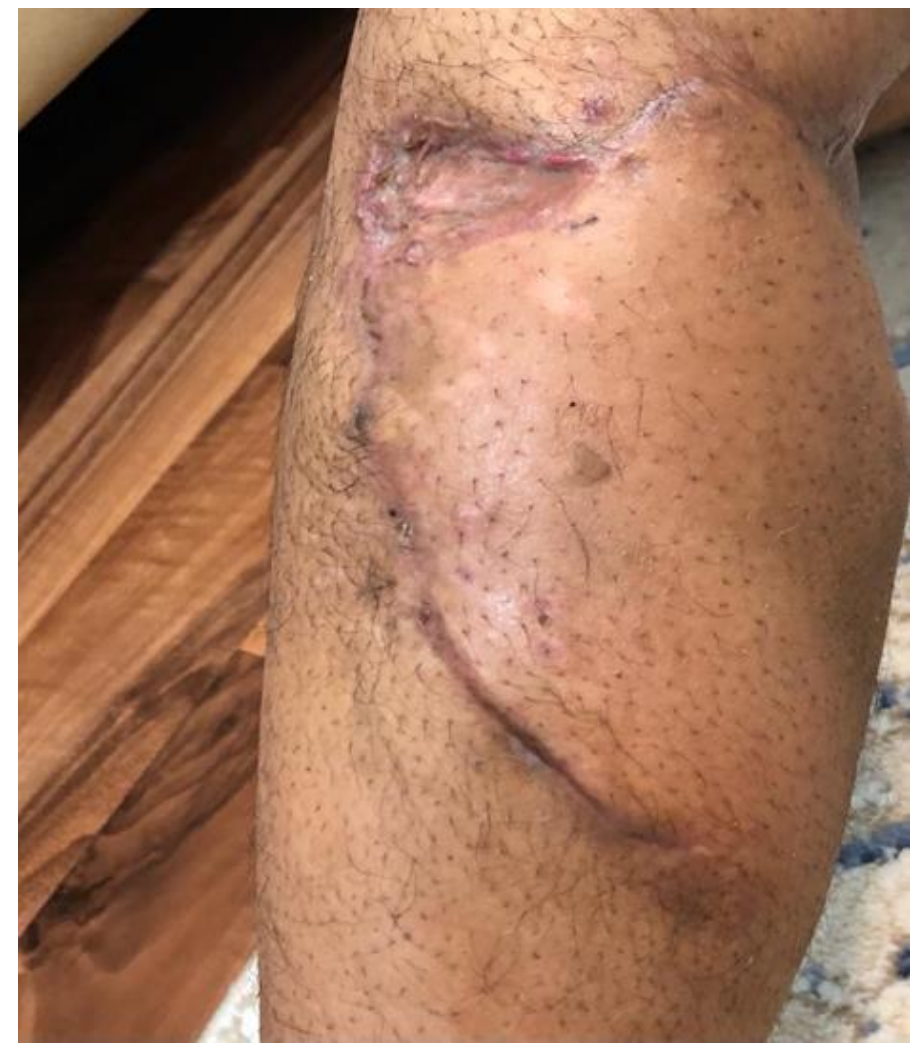

Figure 4: Large mass fixed to the bone and fascia with thick exposed tibial bone and multiple sinuses, which was completely excised and shaved from the muscles and bone

Figure 5: After 3 months of perforator flap coverage.

\section{Discussion}

Actinomyces species are endogenous to the body and live normally within the human microflora mentioned earlier. The pathogenic form is parasitic and occurs when there is disruption of the mucosal barrier and the organism inoculates into soft tissues where there is impaired blood supply ${ }^{[1,7]}$.

As stated above, actinomycosis is most commonly reported in 3 body regions: cervicofacial, abdominopelvic, and pulmonothoracic; however, other rare presentations have also been reported ${ }^{[2]}$.

Reports indicate that actinomycosis can occur in all ages, with a peak inci-dence occurring in the middle decades. It is well reported that males are infected more frequently than females, at a ratio of approximately 3 to $1^{[1,3-5]}$.

Actinomycosis is a difficult disease to diagnose ${ }^{[8]}$. Three important clinical presentations should prompt this diagnosis: 1 . the chronicity of a mass like lesion that extends through tissue borders and mimics a tumor, 2 . the development of sinus tracts that spontaneously resolve and recur, and 3. a relapsing infection following a short course of antibiotics ${ }^{[9]}$.

The drug of choice in the treatment of actinomycosis is penicillin with high dose for prolonged period of time. This allows the antibiotic to penetrate the avascular fibrotic walls of the lesion and reach the core of the sulfur granules ${ }^{[10]}$. For penicillin-allergic patients, alternatives such as tetracycline, doxycyline, erythromycin, and clindamycin may be given ${ }^{[11]}$.

Radiology modalities such as computed tomography or magnetic resonance imaging can be used to monitor therapy success $^{[12]}$.

A few case reports suggest hyperbaric oxygen therapy may be used as an adjunct with antimicrobial and surgical treatment in refractory actinomycosis infections ${ }^{[13,14]}$.

\section{Conclusion}

Primary infection of an extremity is an uncommon and rare feature of actinomycosis. A few case reports suggest that surgical treatment can be used as an adjunct with antimicrobial in refractory actinomycosis infections. We report a case of adult male with primary leg actinomycosis treated with wide local excision and perforator flap.

\section{Ethics approval and consent to participate}

As an ethical consideration, IRB (Institutional Review Board) approval was obtained, Informed consent was clear and indicates the purpose of the study and the right of the participant to withdraw at any time without any obligation towards the study team. Participants' anonymity was assured without personal information for the purpose of case only. The participation in this study was kept confidential and participants' identity will never be revealed, there is no potential conflict of interests that could affect the outcomes of the proposed research.

\section{List of abbreviations}

$\mathrm{mg} / \mathrm{L}:$ Milligram per Liter

GMS: Grocott Methenamine Silver

PAS: Periodic Acid-Schiff

VAC: Vacuum Assisted Closure

\section{Conflicts of Interest}

The authors declares that there is no conflict of interest regarding the publication of this paper. 


\section{Funding Statement}

No funding was received for this study

\section{Authors' contributions}

Norah A was the main author and was responsible for collecting data of case study, and follow patient's condition. Mashael A, help the main author in data collection beside preparing and writing the manuscript and Ayed A, was responsible for analyzed and interpreting biopsy.

\section{Acknowledgments}

Thanks to Allah for this work. Great thanks for our supervisors for their help and support during the study.

\section{References}

[1] Bennhoff D. Actinomycosis: diagnostic and therapeutic considerations and a review of 32 cases. Laryngoscope. 1984;94:1198-1217. [PubMed] [Google Scholar]

[2] Jacob Bettesworth, Kirandeep Gill, and Jayesh Shah, Primary Actinomycosis of the Foot: A Case Report and Literature Review, 2009.

[3] Harvey J., Cantrell J., Fisher A. Actinomycosis: Its recognition and treatment. Ann Intern Med. 1957;46:868-885. [PubMed] [Google Scholar]

[4] Kinnear W., MacFarlane J. A survey of thoracic actinomycosis. Respire Med. 1990;84:57-59. [PubMed] [Google Scholar].

[5] Spilsbury B.W., Johnstone F.R.C. The clinical course of actinomycotic infections: a report of 14 cases. Can J Surg. 1962;5:33-48. [PubMed] [Google Scholar].

[6] Reiner S.L., Harrelson J.M., Miller S.E., Hill G.B., Gallis H.A. Primary actino-mycosis of an extremity: a case report and review. Rev Infect Dis. 1987;9(3):581-589. [PubMed] [Google Scholar].

[7] Bowdon GHW. Actinomyces, Propionibacterium propionicus, and streptomyces. In: Baron S, ed. Medical Microbiology. 4th ed. Available at: http://www.ncbi.nlm.nih.gov/books/bv.fcgi?rid=mmed.c hapter.1863. Accessed July 6, 2009.

[8] Cope Z. Visceral actinomycosis. $\mathrm{Br}$ Med J. 1949;2(4640):1311-1316. [PMC free article] [PubMed] [Google Scholar].
[9] Russo T.A. Agents of actinomycosis. In: Mandell G.L., Bennet J.E., Dolin R., editors. Principles and Practice of Infectious Diseases. 6th ed. Churchill Livingstone; New York, NY: 2005. pp. 2925-2932. [Google Scholar]

[10] Peabody J., Seabury J. Actinomycosis and nocardiosis: a review of basic differences in therapy. Am J Med. 1960;60:99-115. [PubMed] [Google Scholar].

[11] Martin M.V. Antibiotic treatment of cervicofacial actinomycosis for patients al-lergic to penicillin: a clinical and in vitro study. Br J Oral Maxillofacial Surg. 1985;23:428-435. [PubMed] [Google Scholar].

[12] Hawnaur J.M., Reynolds K., McGettigan C. Magnetic resonance imaging of actinomycosis presenting as pelvic malignancy. Br J Radiol. 1999;72:1006-1011. [PubMed] [Google Scholar].

[13] Manheim S.D., Voleti C., Ludwig A., Jacobson J.H., II Hyperbaric oxygen in the treatment of actinomycosis. JAMA. 1969;210(3) 552-523. [PubMed] [Google Scholar].

[14] Shauly Y., Nachum Z., Gdal-On M., Melamed Y., Miller B. Adjunctive hyper-baric oxygen therapy for actinomycotic lacrimal canaliculitis. Graefes Arch Clin Exp Ophthalmol. 1993;231(7):429-431. [PubMed] [Google Scholar].

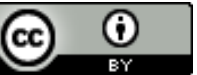

Open Access This article is licensed under a Creative Commons Attribution 4.0 International License, which permits use, sharing, adaptation, distribution and reproduction in any medium or format, as long as you give appropriate credit to the original author(s) and the source, provide a link to the Creative Commons license, and indicate if changes were made. The images or other third party material in this article are included in the article's Creative Commons license, unless indicated otherwise in a credit line to the material. If material is not included in the article's Creative Commons license and your intended use is not permitted by statutory regulation or exceeds the permitted use, you will need to obtain permission directly from the copyright holder. To view a copy of this license, visit https://creativecommons.org/licenses/by/4.0/.

(c) The Author(s) 2021 